\title{
La movilidad de las músicas populares en América Latina en los años 30 del siglo XX. Las voces al unísono*
}

\author{
Mobility of the Popular Musics in Latin America during the 1930s. Voices in Unison
}

A mobilidade das músicas populares na América Latina nos anos 30 do século XX. As vozes em uníssono

Hugo Andrei Buitrago-Trujillo ${ }^{\text {a }}$
Universidad Pontificia Bolivariana, Colombia
hugo.buitrago@upb.edu.co
ORCID: http://orcid.org/0000-0002-9460-5064
DOI: https://doi.org/10.11144/Javeriana.syp38-74.mmpa Redalyc: http://www.redalyc.org/articulo.oa?id=86059657003

\section{Resumen:}

Articulando estudios recientes de la música popular en diversos países de América Latina con las indagaciones hechas en publicaciones como cancioneros y revistas de farándula, se hace una pesquisa sobre la movilidad de las músicas populares por varios países de la región, identificando el incremento, presencia y diálogo de las músicas viajantes con las consideradas nacionales, en la década de los años 30 del siglo XX, momento en el que la industria cultural de la radio, el disco y el cine, en un proceso intermedial, se consolidan como los espacios de entretenimiento y difusión que, con excepción del cine, trascienden los espacios públicos, para instalarse, también, en los escenarios privados.

Palabras clave: música popular, industria cultural, América Latina, radio, discos, intermedialidad, músicas viajantes.

\section{Abstract:}

Articulating, on one hand, some recent studies on popular music from different Latin-American countries and, on the other hand, some searches in publications like song books, and gossip magazines, a research is conducted about the mobility of popular musics through different countries in the region. It identifies the increase, presence and dialogue of the travelling musics with those deemed as national musics during the 1930s. In this decade, the cultural industry of the radio, records and cinema consolidated under an intermedial process as the entertainment and broadcasting spaces that, excluding the cinema, transcend the public spaces to settle into the private spheres.

Keywords: popular music, cultural industry, Latin America, radio, records, intermediality, travelling musics.

\section{Resumo:}

Articulando estudos recentes da música popular em diferentes países da América Latina com as indagações feitas em publicações como cancioneiros e revistas de famosos, faz-se indagação sobre a mobilidade das músicas populares por vários países da região, identificando o acréscimo, presença e diálogo das músicas viajantes com as consideradas nacionais, na década dos 30 do século XX, momento em que a indústria cultural da rádio, discoteca e cinema, em um processo intermidial, consolidam-se como espaços de entretenimento e difusão que, com exceção do cinema, transcendem os espaços públicos, para se instalar, também, nos cenários privados.

Palavras-chave: música popular, indústria cultural, América Latina, rádio, discos, intermidialidade, músicas viajantes.

\section{Introducción}

Los años 30 del siglo XX son un período de alta importancia para la industria cultural, sobre todo en lo referente al espectro musical. En esta década se consolida la radio como medio de comunicación y entretenimiento irremplazable, el cual -en conjunto con los discos y de la mano del cine- se fue instalando

Notas de autor:

\footnotetext{
a Autor de correspondencia. Correo electrónico: hugo.buitrago@upb.edu.co
} 
en la cotidianidad de todo el continente, primero en las zonas urbanas y, posteriormente, en las rurales. Lo anterior permitió llevar al ámbito privado experiencias relacionadas con la audición musical que hasta entonces estaban destinadas a los espacios públicos - sean estos tablados, teatros o actos conmemorativosque se aprestaban para la escucha, la danza o la puesta en escena de representaciones artísticas de diversa índole, y que obligaban la presencia física de músicos.

Al mismo tiempo, las músicas consideradas populares ganaron un espacio en la sociedad que en un principio las miraba con recelo. En este proceso lograron instaurarse como representantes del sentimiento nacional que desde el siglo XIX fue preocupación de las elites latinoamericanas, e ingresar a los salones que las tuvieron vedadas ${ }^{1}$.

Mientras que con el crecimiento de la industria cultural y el acceso de las poblaciones a las músicas foráneas, los públicos se encuentran en un momento de extenso diálogo entre estas músicas que arriban y las que ya utilizaban en sus celebraciones e intimidades. En escenarios académicos, y ante la preocupación de los músicos profesionales, es evidente una amenaza en el terreno que van ganando artistas y músicas extranjeras.

En este marco, en la investigación que da origen a este texto se habla de músicas viajantes para referirse a esas músicas que, en su periplo, arriban, que se instalan y, que a pesar de constituirse en cosmopolitas (Garramuño, 2007; Santamaría-Delgado, 2014), continúan siendo referentes de aquellos lugares y culturas de las que se considera que provienen (Buitrago-Trujillo, 2018).

Huellas de este momento se encuentran en las publicaciones que crecieron con la industria de la música y el cine al sumarse al fenómeno intermedial; cancioneros, revistas de farándula y periódicos de variedades plasmaron el recorrido de los artistas, las canciones preferidas, las músicas que se oían en cada país, y fueron herramienta para el acercamiento de los artistas y sus interpretaciones a los públicos del continente, lo que favoreció, además, la reinterpretación de los mensajes que ofrecían esas canciones.

$\mathrm{Al}$ indagar estas fuentes, y con el apoyo de investigaciones que en los últimos diez años han abordado la música popular de distintos países latinoamericanos, este artículo quiere evidenciar el proceso de movilización y la presencia múltiple de las músicas de Latinoamérica en la región, haciendo énfasis en las antillanas, mexicanas, argentinas y colombianas. Lo anterior con el fin de mostrar que a pesar del debate que se mantenía en las esferas académicas y folclóricas sobre las músicas nacionales, estas penetraron no sólo en el gusto de los públicos, sino también en el de los músicos regionales, quienes entran a formar parte del entramado intermedial en el que el cine, los impresos, la radio, discos y victrolas facilitaron el acceso y reinterpretación de las músicas viajantes.

Para dar cuenta del tema, se presentan cuatro momentos: el primero muestra la perspectiva de las músicas populares nacionales y su relación con la evocación del ensueño campesino o el romanticismo urbano, en el cual descansan parte de los valores que sostienen la idea de nación; el segundo brinda un panorama de la mención, presencia y variedad de artistas de distintas cunas, que tiene lugar en países diferentes al de origen, y de cómo van asumiendo e interpretando aires de estos países, tanto para ingresar en ellos como para no perder vigencia en el propio. Como tercer momento, antes de las conclusiones se hace un recorrido por algunos cancioneros populares, y se contrasta el lugar de publicación con los orígenes de aires, artistas y canciones.

Las fuentes consultadas promueven nuevas inquietudes y se prestan para múltiples preguntas y lecturas que esperan ser formuladas y abordadas por los investigadores. Por lo pronto, este es un ejercicio en el cual se presentan resultados parciales de una investigación doctoral, que inquiere por los diálogos presentes entre las representaciones y la música.

Finalmente, se espera que sea evidente que, antes que ir en detrimento de la afición por una u otra forma musical, la movilidad y el acceso a los aires latinoamericanos ampliaron -mas no reemplazaron- los gustos de la audiencia. Esto se debe a la consolidación de circuitos intermediales y transnacionales que aprovecharon las preferencias y usos regionales para conectar músicas, artistas y públicos, escenario en el que el acceso a estas músicas viajantes en forma diversa fue clave para la aceptación y adaptación de sus mensajes. 


\section{De la nación impopular a lo popular como nación: los escenarios, la radio y los discos}

En la construcción de un ideario nacional, la pretensión inicial de los países Latinoamericanos fue la de emular la música académica europea, permeada por los "aires folclóricos" en algunas versiones; o inspirada desde el "espíritu nacional", en otras. Tal construcción supone, en principio, desdeñar las prácticas musicales de los sectores sociales que aún no han alcanzado el nivel de "civilización" requerido por los parámetros modernos deseados para cada país ${ }^{2}$.

Sea cual fuere el origen, rural o urbano, las músicas a las que se hace referencia en este artículo fueron despreciadas por las élites de sus países de origen, ya sea por la simplicidad y ligereza de sus formas, por su sensualidad explícita o por ser relacionadas con prostíbulos y cantinas. Cada una de ellas fue entendida como una manifestación de la barbarie que era menester combatir en la conformación del Estado moderno.

No obstante, la contradicción permanente entre lo que se consume en las calles y la necesidad de hacer partícipes a los pueblos de un ideario de unión, obliga a la conformación de una imagen aglutinadora que represente los valores de una nación y que sea asequible a los sectores menos letrados del territorio "nacional", en el sentido que una nación obliga al reconocimiento de pertenencia a un grupo, al sentimiento de solidaridad por los miembros de ese grupo, para lo que es vital la construcción de parámetros diferenciadores -como el lenguaje- (Anderson, 1993)en la que la negociación entre poblaciones es una constante preponderante (García-Canclini, 1990.

Es así como se evidencia un círculo de retorno a las expresiones musicales más populares de los países, que las reviste de caracteres nacionales y las somete a procesos de blanqueamiento ${ }^{3}$ y urbanidad, los cuales las sacan de las barriadas y los burdeles para ponerlas en el centro del "espíritu” y someterlas a un performance que escenifique cada "nación”, tanto al interior de las fronteras como en las tarimas del exterior. Según Hobsbawm y Ranger (1983, este retorno opera como invención de la tradición, cuyas formas simbolizan cohesión social o pertenencia a grupos en comunidades reales o artificiales; legitiman instituciones, estatus y relaciones de autoridad; y socializan e inculcan creencias, valores y convenciones de comportamiento.

Aquello se da, y se soporta, con la confluencia de las industrias culturales que se implementaron y crecieron en la primera mitad del siglo $\mathrm{XX}^{4}$-radio, discos y cine-, las cuales transformaron las cotidianidades de las prácticas musicales ampliando el rango de audiencia y de acción, brindando a los públicos una nueva proximidad a la expresión musical y la posibilidad de hallar en los intérpretes dentro de esta intermedialidad (Ochoa-Gautier, 2006), héroes y villanos a quienes odiar o emular.

Como complemento a la producción sonora y cinematográfica, los impresos son un elemento clave en esa difusión; publicaciones de corte privado, con ánimo de lucro, aprovechan la información musical y de farándula, tanto para vender los discos, programas y películas, como para ofrecer productos de belleza, electrodomésticos, servicios farmacéuticos y demás.

Las músicas viajan primero a las ciudades. La migración a las ciudades, si bien tiene un carácter masivo desde la segunda mitad del siglo XX, no es un fenómeno ajeno a la primera mitad de éste. Condiciones de seguridad, trabajo, sueños de modernidad o de fama impulsan la movilización de familias e individuos que llevan consigo sus costumbres, sus cantos y sus bailes. La urbe es la primera escala de las músicas viajantes.

Martín-Barbero (1991), en De los medios a las mediaciones, muestra cómo la confluencia en las urbes latinoamericanas de los años 30, dada por la crisis económica, favoreció la hibridación cultural, y destaca que en este período "el cine en algunos países y la radio en casi todos, proporcionaron a las gentes de las diferentes regiones y provincias una primera vivencia cotidiana de la Nación” (p. 179). Entonces, la radio (su sonoridad) será uno de los principales vehículos de gestión de la comunidad imaginada -retomando a Anderson- que supone la nacionalidad. 
La zamba ${ }^{5}$, y en general la música de la pampa, llega así a Buenos Aires, a disputarse con el tango -urbano per se, condición que comparte con el bolero- y con el gusto de la gente del común, por lo que no es deleznable que la carrera de Carlos Gardel hubiese iniciado en "el folclor" antes que en el tango. Desde los años 20 del siglo XX, Héctor Roberto Chaverro interpreta música del norte argentino en Buenos Aires; y para 1935, Atahualpa Yupanqui ya hacía carrera como difusor folclórico a partir de la investigación (Pujol, 2012).

La revista argentina Sintonía publica su número 70 en agosto de 1934, en el cual, aunque hay una pequeña mención al mexicano Alfonso Ortiz Tirado y notas de artistas estadounidenses y europeos relacionadas con el cine y la música académica, se hace un recorrido por un sinnúmero de exponentes de la música de Argentina - que van desde Libertad Lamarque hasta Enrique Santos Discépolo- e incluye una sección en la que invita a los lectores a adular a sus artistas favoritos, en la que los cantantes argentinos (cantores de folclor) son mayoría ("Elogie ud. a su artista favorito", 1934). Ya sea en teatro, radio o cine, el foco está en los naturales de ese país, y varios de ellos tienen presencia simultánea en estos medios ${ }^{6}$. Más tarde, el número 135 tendrá un comportamiento similar, cuya portada muestra a Eduardo Armani. Esta edición también se centra en los artistas argentinos, sean nuevos o reconocidos, sin excluir al jazz ni las películas estadounidenses, e incluye la partitura del tango "Parece mentira", de De Rodio y Sciammarella, acompañada de sus fotos ("La canción popular”, 1935, p. 67).

Caso atípico parece ser el del bambuco colombiano, el cual, según registra Hernán Restrepo en 1986, tiene sus inicios como música de la bohemia urbana del siglo XIX, para después ser implantado en el campo, y volver con el mismo sabor al paraíso perdido que evoca las pampas, el arado, los caballos o, si se vincula al tango, la antigua barriada.

Para 1930 - como señala Rendón-Marín (2009) al recordar la discusión entre Emilio Murillo y Guillermo Uribe Holguín sobre la división élite-pueblo/urbano-rural- ya existe una idealización de lo bucólico:

Imágenes, textos (entre ellos la música como discurso e imagen sonora) e iconos de la vida del campo sirvieron como recurso que más adelante la industria cultural del siglo XX utilizó para metaforizar y alimentar en las ciudades un imaginario que terminó por velar un escenario muy diferente al sembrado por las guerras partidistas. (p. 59)

Guillermo Uribe Holguín (1880-1971), compositor titulado en la Schola Cantorum y gestor del cambio de la Academia Colombiana de Música en el Conservatorio Nacional (que dirigió en dos períodos), manifestaba, al menos hasta la primera mitad del siglo XX, que la música tradicional del país resultaba pobre para la construcción de una música nacional. Por su parte, el "apóstol de la música nacional”, Emilio Murillo (1880-1942), formado en la Academia Colombiana de Música y discípulo de quien formalizara el bambuco, Pedro Morales Pino, en su momento fue uno de los principales contradictores de Uribe Holguín -así como uno de los encargados de llevar de viaje por varios países los ritmos colombianos-, y se encargó de rescatar y componer varias obras de corte tradicional, y de componer otras que academizaron los aires nacionales de este país.

Más allá de quienes privilegian la música del conservatorio sobre la de las calles, como Uribe Holguín, la consolidación de la radio requiere audiencia, lo que conlleva la programación constante de estas músicas en las emisoras privadas, sin importar los constantes ataques por parte de élites culturales y religiosas. Esto facilitó su aceptación paulatina en las salas de las casas, la cual también se vio favorecida por la transformación de las poesías en letras "más adecuadas" y el supuesto de la aclamación de aquellos ritmos en el extranjero.

La edición del periódico bogotano Estampa del 13 de diciembre de 1941, en una nota sobre el compositor Emilio Sierra, habla de la importancia de la rumba criolla como música autóctona de la capital. En sus declaraciones, el compositor destaca la relevancia de la difusión musical por medio de la grabación de discos - pero con músicos natales-, mientras que el periodista señala que la importancia de Sierra está en que la letra de sus canciones "no está hecha a base de endecasílabos, de grandes poemas centenaristas, o de oraciones líricas, si no con trozos de pueblo, de amorcitos fugaces, de frivolidades que huelen y saben a Bogotá” (Sierra, 1941). Es destacable la entrada del artículo, en letras mayúsculas y al lado del título, la cual se refiere al músico 
- nacido en Fusagasugá, un pequeño municipio cercano a la capital colombiana- quien, hasta la fecha de la nota, nunca había salido de Cundinamarca, departamento en el que su ubica su patria chica:

LA MUSICA BOGOTANA TRIUNFA EN EL MUNDO ENTERO. LA LETRA DE FRANCISO ALMANZA. PORQUE SE LLAMA RUMBA CRIOLLA Y NO FANDANGO. DE LA CABEZA DE SIERRA A NUEVA YORK Y DE AHI A TODO EL CONTINENTE. LA CALLE REAL DE BOGOTA PASEA POR TODA LA TIERRA. - LEAN, QUE 'A JUERGUIAR TOCAN’. (Sierra, 1941, p. 14)

La rumba criolla de Murillo ya es viajante, y sus destinos son la ciudad estadounidense, primero; y el continente americano, después.

Día de la Radio, publicación creada en 1942 por las Damas de la Caridad de Medellín como homenaje a ese medio, presenta imágenes y comentarios de varios artistas que considera relevantes en la historia de las emisoras y de la radio regional ${ }^{7}$. Aparecen, entre otros, Obdulio y Julián, quizá el más reconocido dueto bambuquero del país; al igual que Carlos Julio Ramírez y otros de recorridos diversos que pasaron por los programas radiales. Una de estas imágenes corresponde al Trío de la montaña, tres jóvenes que buscaban personificar la identidad rural andina y su música (ver figura 1). En el pie de foto dice:

'TRÍO DE LA MONTAÑA'. Leonzo Alvarez, Hernán Jímenez y el Mono González, quienes constituían un magnífico conjunto que interpretaba canciones de puro sabor regional, y con quienes se estableció por primera vez, el canto de LAS TROVAS. Leonzo Alvarez, es hoy un prestigioso médico de la ciudad (sic). ( Día de la radio, 1942, p. 23)

En Colombia, estudiantinas y duetos bambuqueros serán los encargados de transmitir en las ciudades esas ideas del campo ideal, la imagen de unos valores previos a la modernización que deben permanecer o, por lo menos, que son dignos de ser añorados. De la mano de las cantoras, una función similar cumplirán en Chile los conjuntos que desde 1927 interpretarán aires de las ruralidades chilenas en Santiago (González, 2013). 


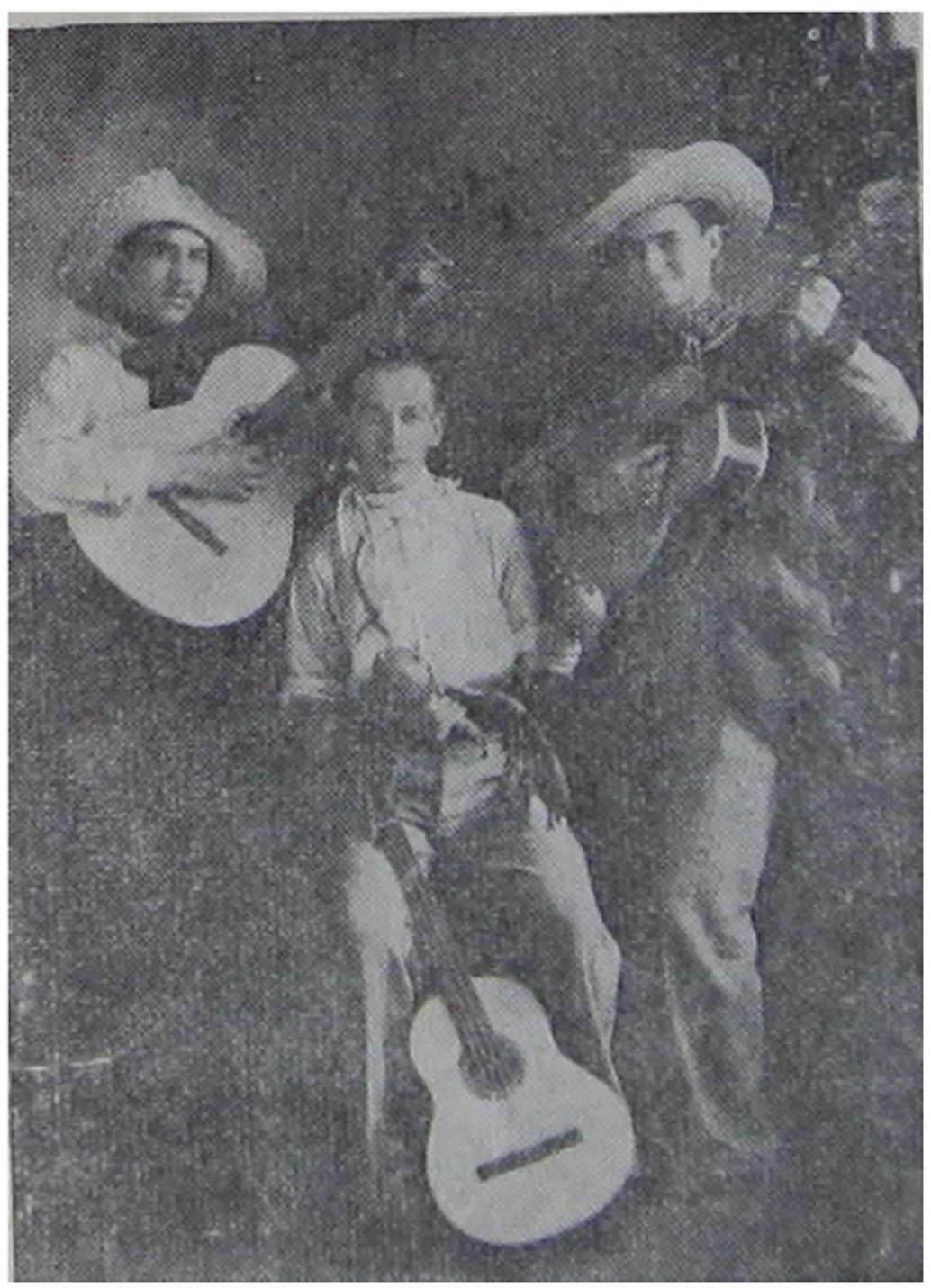

FIGURA 1

El trío de la montaña

Fuente: Día de la radio (1942, p. 23)

Quizá antes que los intérpretes anteriores, la canción yucateca y la ranchera, cuyos exponentes llegan a Ciudad de México, se encargarán de evocar el recuerdo de la vida campirana y expondrán al héroe de los corridos. Más tarde, el bolero, también censurado múltiples veces, evocará el pasado romántico de la ciudad en transformación. Cada género cumplió tareas similares a las arriba mencionadas, como las cumplieron en este caso las voces de los tríos y los mariachis. ${ }^{8}$

\section{Músicas y músicos que viajan}

Como proceso paralelo a la aceptación de las músicas nacionales, el tango es aceptado como representante del espíritu argentino; el bambuco, como representante del sentimiento colombiano; el bolero y la ranchera, como símbolos de México; y la cueca, como aire insignia de Chile. Así mismo, se le suma a cada una de ellas un movimiento folclorista que aboga por su recuperación y difusión. Las músicas foráneas ocupan las preferencias de las masas y empiezan a consolidar un nuevo gusto que irá en detrimento del sentido nacional. $\mathrm{Si}$, como propone Mato (2001), la aceptación y difusión de una música como nacional en el campo de las 
representaciones, supone la definición de una forma de ser y de actuar, es entendible este recelo ante el ingreso de nuevas representaciones no contempladas en el ideario de cada nación.

El furor de los radioteatros y la presencia de discos -ya sea en lugares privados o en las victrolas de los cafés, billares, boliches o heladerías, es decir, en lugares de socialización ${ }^{9}$ - permiten el acceso de las poblaciones a letras y sentidos diferentes de los cotidianos, lo que acentúa el fenómeno intermedial y la posibilidad de contextualizar estas letras en historias mostradas en cine, con rostros que personifican héroes y heroínas que serán modelos para los aficionados.

Volviendo a Día de la radio, la exaltación de las emisoras y sus programaciones gira en torno a la música nacional; sin embargo, en la entrevista que reseña a la recién electa "Reina de la radio", Gloria Echevarría Vélez ${ }^{10}$, su Majestad Gloria I habla de sus escritores colombianos favoritos: Tomás Carrasquilla, Epifanio Mejía, Guillermo Valencia, Gregorio Gutiérrez; y los extranjeros, Gustavo Adolfo Becker y Rubén Darío. De igual manera, resalta su gusto por el cine y los actores estadounidenses, y su admiración por las mujeres de ese país. En cuanto a sus gustos musicales, indica que:

La música española, especialmente las obras de Albeniz, Granados y Falla, la subyugan y atraen. De los boleros, le encantan 'Tengo un nuevo amor', 'Qué pasó y 'Solamente una vez. De las canciones románticas, la seducen 'Alma mía, 'Duerme' y 'Granada'. La mejor cantante de boleros es la mejicana Elvira Ríos, que empieza a hacer furor entre los cantantes suramericanos. ( Día de la radio, 1942, pp. 31-32)

No aparece nada allí del género andino colombiano; no obstante, en otra entrevista del mismo número, la señorita Echevarría dirá, con respecto a otras prácticas musicales:

Lo que nosotros necesitamos es volver a las viejas tradiciones de la familia patriarcal, a las virtudes elementales de la raza. Devoción, hogar, sana alegría de vivir. La Fiesta del maíz, los bailes típicos que hacen ahora, son sencillamente la expresión confusa de un deseo de retorno a lo nuestro. Y lo nuestro en cuestiones familiares es el hogar cristiano, sin divorcios ni complicaciones modernistas. ( Día de la radio, 1942, p. 43)

Son varios los casos en los que se evidencia la adopción de repertorios e imitación de estilos de interpretación, así como son múltiples las versiones hechas por intérpretes locales de aquellas canciones (y bailes) que cruzaron las fronteras, de aquellas músicas viajantes. Antes de las imitaciones de jóvenes rebeldes de las variaciones del club del clan en los distintos países latinoamericanos, es identificable cómo, por ejemplo, el traje de las cantadoras chilenas estuvo inspirado en los vestidos de las campesinas mexicanas hechas ícono en el cine (González, 2013).

Se conoce cómo en Colombia, José María Tena, a mediados de los años 30 del siglo XX, transcribía directamente del programa de Agustín Lara en la XEW - que escuchaba en onda corta- las composiciones que estrenaba el mexicano, para poder presentarlas frescas al día siguiente en el programa Novedad de la Voz de Antioquia. Son varios los nombres de agrupaciones y solistas que no se conformaron solamente con interpretar o componer boleros (mexicanos y antillanos), tangos o pasillos ecuatorianos ${ }^{11}$, sino que también se dedicaron a imitar las formas de aquellos, como Los Cuyitos - fiel imitación de Los trovadores de Cuyo- o las hermanas Domínguez, enfocadas en cantar los temas popularizados por el dúo mexicano de las hermanas Águila.

Roberto Follari (2002) brinda una posible explicación a la asimilación y simultaneidad de estas músicas y temáticas:

La identidad se hace, y siempre es un ser/siendo, una construcción interminable y jamás cerrada, una apertura que no puede clausurarse [...] no existe originariedad (sic) posible de la identidad. No hay identidades autoconstruidas, sino que estas siempre surgen en relación al Otro. Es imposible suponer una cultura que se hubiera constituido sin apelación a elementos 'externos': en realidad, la distinción entre lo externo y lo interno es lo puesto en cuestión. (p. 96) 
En Cuba, Tony Álvarez y Olga Chorens dedicaron parte de su espacio televisivo para difundir tangos y otros aires del sur del continente. El cantante, como se verá adelante, será el referente de identificación de varios tangos publicados en cancioneros cubanos.

La amplia incidencia del bambuco en el desarrollo de la música yucateca, que tendrá exponentes en el bolero como Armando Manzanero (Sánchez, citado en Tello, 2010; Azula, Rodríguez y León, 2011), es documentada por varios folcloristas, melómanos y musicólogos colombianos, y corroborada por su contraparte mexicana.

Varias voces argentinas, como las de Hugo Romani o Leo Marini, desarrollarán una carrera internacional como boleristas, lo que hoy en día no parece un fenómeno tan extraño como lo pudo haber sido para la industria discográfica del país del tango en el momento de la entrada de la competencia de otra música urbana con un sabor más idílico.

En 1936, Sintonía, la revista argentina que antes se mostró centrada en los músicos de su tierra, anuncia la presencia del mexicano Pedro Vargas (quien le merece al crítico de la revista una calificación de cuatro sobre cinco estrellas) y la estancia en tierra porteña de la cubana Esther Borja, reconocida cantante de rumba ("Esther Borja, la cantante cubana”, 1936). Para 1938, la revista de farándula hablaría de "Una electrizante embajada de arte negro americano", sin renunciar a las reseñas cinematográficas, argentinas y estadounidenses, y a la exaltación de los músicos criollos (Klimovsky, 1938). Es notorio, entonces, el cambio en las prioridades de la publicación o, al menos, la ampliación de estas.

Otro ejemplo del movimiento de artistas y de la simultaneidad de las músicas urbanas está en La voz de $R C A$ Victor, suplemento de esta casa disquera editado para Argentina. Si bien la publicación da énfasis a la presentación de las grabaciones de diversas muestras del folclor gaucho y alaba a Hugo del Carril, quien para entonces cumplía dos años de carrera artística, la portada de un número de $1936^{12}$ fue dedicada al músico británico Ray Noble. Pero más allá de la portada, llama la atención la nota dedicada a Pedro Vargas, la cual narra cómo ha grabado boleros en el país gaucho, y la canción "Porteñita mía”, y alude la presencia en Buenos Aires del también cantante mexicano, Juan Arvizu ( La voz de RCA Victor, 1936).

En otro punto del continente se encuentra Radio-guia, una revista de farándula cubana que presenta en una portada de $1942^{13}$ al actor y cantante mexicano Tito Guizar ${ }^{14}$-y hace alusión a la visita del artista a la isla caribeña-, mientras que la imagen de contraportada se la dedica al tanguero Manolo Fernández. Las 116 páginas de la revista hablan, por supuesto, de los artistas cubanos que ocupan los programas radiales, pero a la vez refiere cantantes estadounidenses, y señala el éxito en La Habana de Pedro Vargas, Esther Borja y el mencionado Guizar (Hits Radiofónicos, 1942).

Esta trascendencia musical es un fenómeno que se da, en gran medida, gracias a la movilidad a la que la industria musical obligaba a los artistas. Focos de grabación como México, en primera instancia, luego Buenos Aires y finalmente Medellín ${ }^{15}$, se consolidarían como bases de importantes disqueras, así como de la contratación exclusiva de estrellas reconocidas que serían presentadas en radioteatros, centros de espectáculos y programas radiales. Estos medios y escenarios se constituyen en puente de cercanía y camino de difusión: los puertos y vehículos de las músicas viajantes.

Si ante las influencias de las bandas de jazz estadounidenses ya se habían conformado las orquestas típicas argentinas, como las de D’Arienzo, Troilo, Calo, Pugliese, Canaro, De Angelis, Piazzolla; y las orquestas tropicales colombianas, como las de Lucho Bermúdez y Pacho Galán, solo faltaba la incorporación formal de las otras músicas a los repertorios cotidianos. Así, los grupos de cuerda chilenos, los mariachis y estudiantinas, y los duetos bambuqueros se vieron obligados a incorporar en sus repertorios esas canciones que, desde afuera, amarraban a los públicos nacionales que esperaban tararear, bailar y brindar al ritmo de esas melodías, las cuales, según varios folcloristas, amenazaban de manera radical la lealtad al ideario nacional que con las letras y músicas - bucólicas o urbanas- se había logrado edificar a través del tiempo. Esas músicas que la élite anterior había despreciado por ser del campesino o del obrero, son las que la élite actual buscaba recuperar ${ }^{16}$. 


\section{La gente canta}

Una forma de mercadeo de los patrocinadores de los espectáculos y de las disqueras es la venta y reparto de cancioneros que promocionan, además de las canciones, a los artistas que versionan y a las marcas auspiciadoras. $\mathrm{Al}$ parecer, el éxito de esta práctica fue tal que varias editoriales y algunas imprentas menores iniciaron la publicación periódica de estas revistas y folletos. A la presentación de letras como una forma de llegar a la audiencia, se suman secciones de periódicos noticiosos y revistas de farándula.

El público de las publicaciones es variado: jóvenes, amas de casa y sectores menos favorecidos que seguramente ven compensadas las dificultades para leer, dados los bajos niveles de alfabetización, con el reconocimiento de los artistas y la familiaridad que les da haber conocido las canciones a través de la radio, el cine y las victrolas; así como la reinterpretación de los mensajes que les brindan, por estos medios, las canciones.

Junto con la difusión de estos impresos, también se evidencian los esfuerzos de folcloristas por publicar compilaciones de músicas bucólicas. Esta simultaneidad hace evidente la variedad de la escucha en un momento en el que cada vez son menos los programas radiales dedicados a las músicas locales (Rendón-Marín, 2009; Tello, 2010.

En 1942, Radio-guía dedica cinco páginas a letras de canciones que denomina 'Hits Radiofónicos', y entre las 14 letras que brinda a sus lectores aparecen composiciones de los boricuas Titi Amadeo, Roberto L. Cole, Pedro Flores y Daniel Santos, así como del mexicano Abel Domínguez, quien anuncia que interpretará al famoso trío cubano Servando Díaz, a su regreso de Puerto Rico. De igual manera, a modo de cierre de sección se presentan tres letras de los éxitos cantados por Tito Guizar ${ }^{17}$.

También en Cuba, y en el mismo año, circula Melódico, un cancionero con algunas notas y rumores de farándula, que en su número 32 publica las letras de más de 40 canciones $^{18}$, algunas identificadas con su autor; y otras, con el intérprete que las popularizó (o esperan los patrocinadores que popularice. En el listado se identifican un espectro amplio de aires y regiones, como una versión en español de Ciribiribin, tonada italiana que pasó por varias versiones, incluida la de Frank Sinatra en 1939, que seguramente es base de la que aquí presentan (Melódico, 1942.

De igual manera, entre las letras publicadas está "Rica pulpa", a cuyo pie de título no aparece su compositor, sino el nombre del colombiano que la inmortalizó, Carlos Julio Ramírez, a quien le dedican, además, sus páginas centrales. En adición, muestra canciones interpretadas por la argentina Libertad Lamarque, en su mayoría identificadas con la cantante y la película en la que las cantó; y valses, tangos y boleros de compositores, como el puertorriqueño Rafael Hernández, el uruguayo Francisco Canaro, los mexicanos Abel Domínguez, Agustín Lara, Miguel Prado y Gabriel Luna, y los argentinos Gregorio Ayala, Guillermo Barbieri y Hugo del Carril. Además, muestra tangos popularizados por Tony Álvarez, el cantante cubano de altísima recordación que ya se ha mencionado. Por supuesto, a la par con esta amplia lista, aparecen canciones de cubanos como Nico Saquito, Julio Cueva, Bobby Collazo y Armando Oréfiche.

Algunas de las canciones que allí aparecen y que trascendieron al continente y el tiempo son: Yo no sé qué me han hecho tus ojos, vals de Francisco Canaro, interpretado por Ada Falcón, Carlos Gardel, Julio Jaramillo - para mencionar apenas tres-; el bolero Duerme, de Miguel Prado, que cantaron Los Panchos, Pedro Infante, Javier Solís, entre otros; el bolero Solamente una vez, de Agustín Lara, el cual tiene incontables versiones; y Hay que saberperder, bolero del mexicano Abel Domínguez, también interpretado por Julio Jaramillo, Daniel Santos y Antonio Aguilar.

Dos años antes, en Medellín se publicaba el número 21 del cancionero Discograma (1940), con 64 letras, de las cuales más de 30 son de autoría del puertorriqueño Rafael Hernández; al menos cuatro son de Agustín Lara, y otro tanto se presentan como cantadas o compuestas por Pedro Vargas ${ }^{19}$. También aparecen los nombres de los mexicanos Juan Arvizu ${ }^{20}$, Jorge del Moral; una vez más, Tito Guizar, e incluso alguna canción 
de la película estadounidense Balalaika. En la estructura del cancionero no es constante la aparición del género o de los intérpretes. Por ejemplo, la canción ranchera Tú, solo tú ${ }^{21}$, de Felipe Valdés Leal, no tiene ninguna información diferente al título, como si se sobreentendiera que el lector la reconocerá; a la vez, $O b$ Johny (Oh Johny, ob Johny) es referida a su intérprete, la colombiana Sarita Herrera. Cabe aclarar que en este maremágnum de boleros, boleros-tango, guarachas, rancheras y demás, no llegan a 10 las letras de canciones identificables como aires colombianos - una de ellas proviene de la película nacional Flores del valle ${ }^{22}$.

El número de febrero del año siguiente de Discograma ampliará su panorama con la música cubana con Ernesto Lecuona, por ejemplo. Se mantienen los ídolos mexicanos y se da mayor espacio al tango con letras de Juan de Dios Filiberto ${ }^{23}$ y Agustín Magaldi, entre otros. Llama la atención que bajo el título de la Guavina Chiquinquireña (sic), una de las canciones insignes de la música colombiana, se prefiere poner el nombre del cantante mexicano Pedro Vargas ( Discograma, 1941a) -quien la interpretó- al de sus autores, los colombianos Daniel Bayona y Alberto Urdaneta. De igual manera, en la misma publicación aparecen las hermanas Águila y Guty Cárdenas ${ }^{24}$. Como representación de la música andina colombiana, se publican canciones interpretadas por el dueto Ospina y Peláez, cuyos bambucos, pasillos y valses aparecen en menor proporción que las músicas que viajaron a Colombia, pero que no dejan de tener espacio en el cancionero -en el que también aparece una obra del reconocido compositor de aires andinos colombianos, Emilio Murillo ( Discograma, 1941a).

Para diciembre del mismo año, el cancionero presenta pequeñas biografías de los artistas internacionales y nacionales acompañadas de fotos de artistas mexicanos, como Lupita Palomera, Chucho Martínez, Pedro Vargas; colombianos, como Obdulio y Julián, Carlos Julio Ramírez; argentinos, como Carlos Gardel (con una nota extensa); y puertorriqueños, como Rafael Hernández. Otros artistas colombianos -como Pepe Ebri, los hermanos Hernández e Isabel Rubio- aparecen también en las imágenes, aunque estas son más pequeñas y con referencias más escuetas ( Discograma, 1941b).

Bajo el título de Cancionero antioqueño ${ }^{25}$, en Medellín es editada una revista que en 1940 entregaba a sus lectores la poesía de canciones como ${ }^{26}$ : Tengo mil novias, Oh Johny, El huerfanito, Mi noche triste, Lamparilla y Salud, dinero y amor ( Cancionero antioqueño, 1940). En su inventario, la compilación antioqueña cuenta con varias de las canciones interpretadas por Pedro Vargas, Juan Arvizu, Hugo del Carril y Alberto Gómez - esto es, bolero mexicano, vals, canción y tango, que se mezclan con boleros-guaracha-, y a la vez, si no en igual, en menor proporción ${ }^{27}$, aparecen valses, bambucos y pasillos colombianos. El cancionero responde, entonces, a las músicas que consumen los antioqueños más que a la que se produce en Colombia.

\section{Conclusiones}

Los artistas del continente - a la vez que viajan, primero para grabar y luego para presentarse en los radioteatros y emisoras radiales - articulan aires de los países visitados a sus repertorios, como estrategia de ingreso a los mercados y de cercanía con las audiencias. Un caso diciente es el de Pedro Vargas, quien pasa de la guabina al tango, y de allí al bolero antillano, mientras promociona al bolero mexicano por el Caribe y el sur del continente. El "Ruiseñor de las Américas", en la década en cuestión, se presentó, fuera de su país, al menos en Cuba, Estados Unidos, Puerto Rico, Venezuela, Argentina y Colombia.

De esta práctica devienen tres aspectos principales. En primera medida, la adecuación de canciones locales a ritmos foráneos para facilitar su interpretación por parte de los artistas en promoción abrió posibilidades sonoras a los músicos populares que accedían al nuevo repertorio mediante la radio y los discos (SantamaríaDelgado, 2014). En segundo lugar, tal exposición afectará composiciones y manifestaciones futuras, lo que permite ampliar las prácticas musicales de las audiencias que, incluso, encontraban en las dos caras de un mismo vinilo un aire nacional y uno extranjero, interpretados por el mismo artista. En tercer lugar, las 
canciones vinculadas al repertorio de los artistas y sus arreglos también se vuelven viajantes y son conocidas en otros extremos del continente.

El origen privado y el carácter comercial de las revistas y cancioneros hacen suponer que sus contenidos esperan agradar y llegar a los lectores, esto es, vender. La variedad de productos y servicios que se publicitan en ellas dan cuenta de ello. Si a esto se suma la presencia de programas radiales especializados en músicas de latitudes diferentes a las del país de emisión, se hace evidente el gusto y consumo real de estos aires en las urbes latinoamericanas. Lo anterior no obsta del mantenimiento, en los impresos y los programas, de géneros y artistas nacionales que entran a complementar el espectro musical de las audiencias y lectores.

La ampliación de las preferencias musicales y la inserción de estas nuevas músicas y bailes en la cotidianidad de las poblaciones latinoamericanas mediante un proceso intermedial, obligaron a los grupos musicales nativos que acompañaban las celebraciones de la sociedad a adoptar formatos, repertorios e, incluso, a imitar ritmos, canciones y artistas que eran del gusto popular -debido a los discos, la radio y el cine-, sin renunciar a la interpretación de aires considerados tradicionales o propios.

Finalmente, un asunto que merece una mirada profunda es el papel del cine en esa circulación musical. Las películas argentinas, mexicanas y estadounidenses no sólo fueron vehículo de difusión de los músicos dentro y fuera de sus fronteras, sino que también promovieron, quizá a partir de la exotización, nuevas formas de ver y hacer las músicas, como se intuye en los casos de Libertad Lamarque, Carlos Julio Ramírez o Carmen Miranda.

\section{Referencias}

Anderson, B. (1993. Comunidades imaginadas. México D. F.: Fondo de Cultura Económica.

Aretz, I. (2007. América Latina en su música. México D. F.: Siglo XXI-Unesco.

Azula, M., Rodríguez, M., y León, L. (2011. Canción andina colombiana en duetos. Transcripción y aproximación documental. Bogotá: Universidad de los Andes.

Buitrago-Trujillo, H. A. (2018. Un pandemónium de ridiculas estridencias. Prácticas musicales y representaciones sociales durante La Violencia en los Llanos orientales y Tolima (tesis doctoral). Universidad Nacional de Colombia, Medellín, Colombia.

Cancionero antioqueño. (1940, 1.o de septiembre). XII(69).

Cancionero colombiano. (1940, 7 de octubre). XV(144).

Cancionero colombiano. (1941, 24 de enero). XVI(150).

Cortés-Polanía, J. (2004). La música nacional popular colombiana en la colección Mundo al día (1924-1938). Bogotá: Universidad Nacional de Colombia.

Dia de la radio. Publicación oficial de las festividades de la radio organizadas por "Las damas de la Caridad". (1942, 11 de agosto). (1).

Discograma. (1940, 26 de junio). $I V(21)$.

Discograma. (1941a, 26 de febrero). $V(28)$.

Discograma. (1941b, 1 de diciembre). $V(35)$.

"Elogie ud. a su artista favorito". (1934, 25 de agosto). Sintonía, 2(70), 44-45.

"Esther Borja, la cantante cubana, recibió su bautismo porteño de tango". (1936, 13 de junio). Sintonía, 4(164), 28-29.

Follari, R. (2002). Identidad cultural e intervención técnica. Temas y problemas de comunicación, 10(12), 91-100.

García-Canclini, N. (1990). Culturas híbridas. Estrategias para entrar y salir de la modernidad. México D. F.: Grijalbo. García-Canclini, N. (2007). Lectores, espectadores, internautas. Barcelona: Gedisa.

Garramuño, F. (2007). Modernidades primitivas. Tango, samba y nación. Buenos Aires: Fondo de Cultura Económica. González, J. (2013). Pensar la música desde América Latina. Buenos Aires: Gourmet musical. 
Hits Radiofónicos. (1942, marzo). Radio-guía. Revista mensual de radio nacional e internacional, VIII(93), 30-34.

Hobsbawm, E., y Ranger, T. (eds.). (1983). La invención de la tradición. Barcelona: Crítica.

Klimovsky, L. (1938, 2 de junio). Una electrizante embajada de arte negro. Con la "troupe" negra del teatro Avenida. Sintonia, 6(267), 7-8.

"La canción popular". (1935, 23 de noviembre). Sintonía, 3(135), 67.

La voz de RCA Victor. Suplemento mensual. (1936, noviembre). IV(11).

Martín-Barbero, J. (1991). De los medios a las mediaciones. México D. F.: Gustavo Gili.

Mato, D. (2001). Producción transnacional de representaciones sociales y transformaciones sociales en tiempos de globalización. En D. Mato (comp.), Estudios Latinoamericanos sobre cultura y transformaciones sociales en tiempos de globalización (pp. 13-29). Buenos Aires, Argentina: CLACSO.

Melódico. (1942, junio). $V(32)$.

Ochoa-Gautier, A. M. (2006). El sonido y el largo siglo XX. Número, (51), 1-9.

Pérez-González, J. (2010). Las historias de la música en Hispanoamérica (1876-2000). Bogotá: Universidad Nacional de Colombia.

Puerta-Domínguez, S. (2015). Cine y nación. Negociación, construcción y representación identitaria en Colombia. Medellín: Universidad de Antioquia.

Pujol, S. (2012). Cien años de música argentina desde 1910 a nuestros dias. Buenos Aires: Biblos-Fundación OSDE.

Rendón-Marín, H. (2009). De liras a cuerdas. Una historia social de la música a través de las estudiantinas, Medellín, 1940-1980. Medellín: Universidad Nacional de Colombia-Sede Medellín.

Santamaría-Delgado, C. (2014). Vitrolas, rocolas y radioteatros. Hábitos de escucha de la música popular en Medellín 1930-1950. Bogotá: Pontificia Universidad Javeriana/Banco de la República.

Sierra, E. (1941). Qué vivan los novios. Estampa, XI(160), 14-43.

Tello, A. (coord.). (2010). La música en México. Panorama del siglo XX. México D. F.: Fondo de Cultura Económica/ Conaculta.

\section{Notas}

* Artículo de investigación El artículo que se presenta es resultado de la investigación Un pandemónium de ridículas estridencias. Prácticas musicales y representaciones sociales durante La Violencia en los Llanos orientales y Tolima (1942-1965), desarrollada para acceder al título de Doctor en Historia de la Universidad Nacional de Colombia, Sede Medellín. Esta investigación fue favorecida por del Programa Nacional de Apoyo a estudiantes de posgrado para el fortalecimiento de la investigación, creación e innovación de la Universidad Nacional de Colombia 2013-2015.

1 Desde el siglo XIX, se presenta una discusión constante sobre los parámetros de la construcción de la música nacional en distintos países de América Latina, una corriente plantea que ésta debe estar en el ámbito de lo académico bajo los estándares occidentales; y otra, que debe ser la recuperación de los aires campesinos. Dicha discusión persiste aún en la segunda mitad del siglo XX, como se puede ver en Aretz (2007).

2 Acerca de la discusión y debates sobre música nacional y música latinoamericana en la primera mitad del siglo XX, ver Juliana Pérez-González (2010); y para el caso colombiano, Jaime Cortés-Polanía (2004).

3 El proceso de blanqueamiento se da en múltiples escenarios. La internacionalización, como en el caso del tango argentino y el samba brasileño, no es suficiente, también es necesario suavizar el contenido -sexual, grosero o político- (Garramuño, 2007).

4 La transformación y la confluencia de las industrias culturales conlleva a la modificación de las relaciones entre los públicos (audiencias) y los productos de estas industrias que, según Néstor García-Canclini (2007), pasan del lector al espectador e internauta, no necesariamente de manera excluyente.

5 Asumimos la samba como el género musical brasileño y la zamba como el aire musical argentino. 
6 Esta revista, al igual que varias de las que se relacionan en el artículo, muestra la programación diaria de varias emisoras. Además, en los distintos números de la revista se verán, al lado de las referencias de jazz estadounidense, reseñas de músicos argentinos dedicados a este género, y algunas letras en inglés y traducidas que invitan a aprender a cantar en el idioma anglo.

7 En este número se hace una exaltación de las principales emisoras antioqueñas, sus directores, programas y locutores que hicieron parte de ellas (La Voz de Antioquia, Ecos de la Montaña, Claridad, Siglo XX, La voz del triunfo y Universidad de Antioquia) ( Dia de la radio, 1942).

8 Ver en Tello (2010) a Martín y Vega (pp. 253-290); Ortiz (pp. 291-307) y Monsiváis (pp. 180-252).

9 Sergio Pujol (2012) narra cómo el sector obrero de Buenos Aires llegó a ser reconocido por la costumbre de dejar una porción de menguado salario para compartir una pizza y programar canciones en las victrolas. Para Colombia, Carolina Santamaría-Delgado (2014) dará cuenta de la diferencia del listado de discos conforme el establecimiento, el tipo de concurrencia y las expectativas de socialización.

10 La ganadora del concurso de belleza organizado por Las Damas de la Caridad, proviene, según la misma entrevista, de "uno de los más prestigiosos colegios de la ciudad” y vive al margen izquierdo de la Playa, uno de los sectores más prestigiosos de la ciudad, lo que, sumado al apellido, da cuenta de su origen privilegiado.

11 Nelson Pinedo, Olimpo Cárdenas, Tito Cortés, "El Caballero Gaucho”, Alci Acosta, José Barros, Jorge David Monsalve Velásquez "Marfil”, entre otros.

12 El número refiere 48 nuevos discos de dos canciones cada uno, de ellos, tres pertenecen a la línea de música académica, cinco a canciones de películas y los 40 restantes se distribuyen entre nueve de foxtrot interpretados por bandas de jazz estadounidenses, tres de música cubana (entre los que aparece el grupo de Ernesto Lecuona), y los 26 restantes están dedicados al folclor de los países del sur del continente, especialmente zamba, chamame y tango argentinos, y algunos temas bolivianos y paraguayos ( $L a$ voz de RCA Victor, 1936).

13 Aunque no es un ítem de análisis en el artículo, es necesario destacar que en la parrilla de programación de las emisoras que ofrece esta revista, al igual que en varias otras guías de distintos países, es evidente la presencia de programas permanentes dedicados a músicas foráneas, en este caso, bajo nombres como Música argentina, Música española o, simplemente, Música americana.

14 Intérprete reconocido de rancheras y bolero ranchero.

15 Según Carolina Santamaría-Delgado (2014), el hecho de que Gardel se convirtiera en mito en la capital antioqueña se da por la costumbre que adquirieron los artistas extranjeros como Gloria Guzmán, María Luisa Landin, Juan Arvizu y Libertad Lamarque, de hacer una ofrenda al tanguero en el lugar de su muerte cuando arribaban a la ciudad.

16 No obstante, compositores como Alejandro Wills, Emilio Murillo y Luis A. Calvo, de reconocida trayectoria en la composición andina colombiana, cuentan en sus obras con tangos, danzones y zambas, como consta en los registros de Mundo al día, recogidos por Jaime Cortés-Polanía (2004).

17 Las canciones cuyas letras aparecen en la revista son: Borracho no vale, Venganza, Yo no sé nada y Despedida de Pedro Flores; Guaracha amorosa, de Titi Amadeo; Mayorá de Daniel Santos; Olvídame, de Roberto L. Cole; A-E-I-O-U, de Elena de Arcos; Yo no te olvidaré, de Monchy de Arcos; Hay que saber perder, de Abel Domínguez; Vivir para ti, de Horacio Arredondo Sosa; las cantadas por Tito Guizar son Los tres, Allá en la Argentina (ambas del propio Guizar) y Ella, del cubano Osvaldo Farrés (Hits Radiofónicos, 1942).

$18 \mathrm{Al}$ igual que la revista Sintonía de Argentina, Melódico publica, en su sección Let’s sing in English, canciones en inglés, y ofrece 11 letras, varias de ellas tomadas de películas.

19 Entre estas se encuentra Amor del bohio, del dominicano Ramón Emilio Jiménez.

20 Salud, dinero y amor, canción interpretada por Arvizu y cuya letra aparece en Discograma, ha sido quizá la versión más reproducida en el país a través de los años.

21 La cantaron Pedro Vargas, Luis Aguilar, Pedro Infante y muchos más.

22 La película, estrenada en 1941, es considerada el primer largometraje sonoro colombiano. Entre sus actores contó con reconocidos artistas radiales y apela a la fórmula melodrama-música en su historia (Puerta-Domínguez, 2015).

23 Conocido por la composición de "Caminito". 
24 Precisamente Guty Cárdenas será uno de los exponentes de la música yucateca influenciada por el bambuco.

25 En el mismo año y también en Medellín se edita el n.o 144 del Cancionero colombiano (1940), cuyo contenido se aparta poco del listado que aquí se presenta. Al parecer ambos cancioneros están patrocinados por Discos Victor.

26 No son pocos los casos en los que, como se supondrá, las canciones que aparecen en un cancionero se repiten en otros, asignadas al mismo o a otro intérprete; asunto que se ha tratado de obviar en el transcurso del relato, para favorecer un mayor número de títulos. No obstante, para dejar constancia de que sucede, se señala que canciones como Ob Johny o Salud, dinero y amor fueron publicadas el mismo año en el cancionero Discograma.

27 Una excepción que contiene mayoritariamente canciones de la música andina colombiana es el Cancionero colombiano n.o 150, que presenta varios temas del repertorio del dúo Ospina y Peláez ( Cancionero colombiano, 1941).

\section{Licencia Creative Commons CC BY 4.0}

Cómo citar este artículo: Buitrago-Trujillo, H. A. (2019). La movilidad de las músicas populares en América Latina en los años 30 del siglo XX. Las voces al unísono. Signo y Pensamiento, 38(74). https://doi.org/10. 11144/Javeriana.syp38-74.mmpa 